4 Seed dormancy depth is partitioned more strongly between habitats than between species in tropical ephemerals

- ${ }^{1}$ Centre for Mine Site Restoration, Department of Environment and Agriculture, Curtin University, GPO Box U1987, Bentley WA 684, Perth, Australia

$-{ }^{2}$ Kings Park and Botanic Garden, Kings Park, WA 6005, Perth, Australia

- ${ }^{3}$ School of Biological Sciences, The University of Western Australia, 35 Stirling Highway, Crawley WA 6009, Perth, Australia.

- ${ }^{4}$ Corresponding author (Adam.Cross@curtin.edu.au)

Running title: Seed dormancy variation in tropical Byblis

Additional keywords: Byblis, afterripening, ethylene, germination biology, seed dormancy, smoke, stratification, physiological dormancy

Seed biology in the annual herbaceous flora of ecologically stressful, seasonally wet habitats remains largely unexplored. Temporal and spatial species turnover between these habitats is often high, yet little is known about how fine-scale habitat variation drives intraspecific variability in seed dormancy depth and seed germination requirements. This study characterised seed dormancy and investigated the germination biology of six closely-related herbaceous annual species of Byblis from northern Australia. We assessed variation in the response of seeds of all species to temperature cues, as well as light and the naturally occurring germination stimulants $\mathrm{KAR}_{1}$ and ethylene. We also examined intraspecific variation in germination response and seed dormancy depth for three widely-distributed species with overlapping distribution occurring in habitats with differing soil thermal and hydrological conditions. Seed germination in all six species was significantly increased by exposure to either $\mathrm{KAR}_{1}$ or ethylene with this effect amplified in two species (B. filifolia and B. rorida) following a period of warm, dry afterripening. Seed dormancy depth and the germination response of seeds to both $\mathrm{KAR}_{1}$ and ethylene was partitioned more strongly between habitats than between species. Populations on shallow ( $<20 \mathrm{~cm}$ soil depth) sandy soils produced less dormant seeds than populations of the same species on deeper sandy soils $(40+\mathrm{cm})$ or on heavy cracking clays. The upper soil profile of shallow soil habitats was exposed to higher average temperatures, greater diurnal temperature fluctuation and greatly reduced moisture persistence compared to deeper soils. Fine-scale differences in the thermal and hydrological conditions of seasonally wet habitats appear to be strong drivers of dormancy depth in seeds of tropical Byblis. Widely-distributed species exhibit high levels of plasticity in seed dormancy depth and germination response between different habitats, with similar responses observed for sympatric species. In order to fully understand species turnover in tropical ephemerals, future studies should examine phenotypic plasticity and the rate of local adaptation of seed traits in greater detail. 
The seasonality of precipitation in tropical regions is a major ecological driver of plant traits, with increasing duration and intensity of the drought period strongly selecting for annual species reliant upon the formation of persistent seed banks (Clary 2008; Cross et al. 2015a,b). Seasonality appears to have driven the assembly of a diverse suite of annual species in the flora of northern Australia; annual herbs, forbs and grasses represent at least half of the ca. 8000 plant species in the region (AVH 2016; Bostock and Holland 2016; Northern Territory Herbarium 2016; Western Australian Herbarium 2016). The richness of annual species is particularly high in ephemeral, seasonally wet habitats; these ecosystems are mostly rain-fed and may be waterlogged or flooded for weeks or months at a time during the wet season but dry rapidly and completely after the cessation of seasonal rainfall (McKenzie et al. 2009). Ephemeral habitats may experience drought periods even during the summer wet season, with high evaporation and unpredictable rainfall often resulting in extended dry periods between inundation events (Cross et al. 2015a,b). Species turnover in these habitats is often high (e.g., Krieger et al. 2003; Cross et al. 2015b), and they harbour numerous ecological specialists including some highly localised rare species ( $<20 \mathrm{~m}$ known range) such as Schoenus kimberleyensis and Trachymene pavimentum (Barrett and Barrett 2015). However, the reproductive ecology of tropical annuals in northern Australia remains predominantly unexplored. Little is known about how habitat ephemerality acts as a selection pressure on recruitment and as a driver of species turnover, and how this pressure varies spatially (e.g., at scales from metres to kilometres and across different substrates) and temporally (e.g., within and between seasons).

Variation in the depth of seed dormancy within and between populations can be affected by factors in the parental environment during seed maturation, as well as by genetic effects (Donohue and Schmitt 1998; Cochrane et al. 2015).

A charismatic element of the annual herbaceous flora of seasonally wet habitats in northern Australia is the remarkable abundance and diversity of carnivorous plants (ca. 85\% of which are annual herbs; Lowrie 2014). The region harbours around 40 of the ca. 200 species of Drosera (Droseraceae), three of the ca. 160 species of Nepenthes (Nepenthaceae), at least 60 of the ca. 230 known species of Utricularia (Lentibulariaceae) and, notably, six of the eight species of Byblis (Byblidaceae). All six tropical Byblis species are barochorous annuals reliant upon extensive soil seed banks for seasonal recruitment (Lowrie 2014; A. Cross unpubl.), and all occur in seasonally wet areas such as riparian lowlands, marginal aquatic environments or temporary flush and seepage zones (Lowrie and Conran 1998; Lowrie 2014). Four species are widely distributed, with B. rorida occurring throughout the northwest Kimberley, B. filifolia common 
throughout the Kimberley as well as the Top End of the Northern Territory, B. aquatica known from disjunctive areas in the northwest Northern Territory and far northeast Queensland, and B. liniflora widespread throughout northern Australia as well as extending into southern Papua New Guinea (Lowrie 2014). In contrast B. guehoi is known from only a small area on the Dampier Peninsula in the western Kimberley (Lowrie and Conran 2007), and B. pilbarana is restricted to seepage habitats in the semi-arid northwest Pilbara in Western Australia (Lowrie 2014).

Seed dormancy and germination biology of annual plants in northern Australia remains predominantly unexplored, and the germination requirements of tropical Byblis species in particular remain completely unresolved. However, seeds of diverse taxa from northern Australia are known to exhibit a range of germination responses to factors such as temperature, light, wetting and drying cycles, soil disturbance, burning cycles and microsite variation (e.g., Setterfield 2002; Turner and Dixon 2009; Cross et al. 2014, 2015a). Previous research suggests that Byblis produce physiologically dormant seeds (Cross et al. 2013). Seed germination in species with physiological dormancy from ephemeral habitats in northern Australia is often increased after periods of warm, dry afterripening simulating seasonal drought and warm dry soil storage (Cross et al. 2015a). Additionally, ethylene is an important germination cue for seeds of species inhabiting wetlands in many parts of the world (Baskin and Baskin 2014). In fire-prone habitats, such as the kwongan in south west Western Australia, germination ecology frequently manifests as an interplay between dormancy break and fire-related cues such as the smoke-derived $\mathrm{KAR}_{1}$ (Flematti et al. 2004; Merritt et al. 2007). Ethylene has been found to elicit strong germination in several species of wetland annuals from northern Australia (Cross et al. 2014), and fire is an intrinsic component of the highly seasonal ecology of northern Australia with savanna habitats considered to be among the most fire-prone ecosystems on the planet (Russell-Smith and Yates 2007; McKenzie et al. 2009; Bowman et al. 2010; Andersen et al. 2012). Extensive post-fire recruitment has been observed for several tropical Byblis species (Cross et al. 2013; Lowrie 2014), and fire has been implicated as a crucial mechanism in the ecology of both species of Byblis from south west Western Australia (Conran et al. 2002; Cross et al. 2013; Lowrie 2014). Smoke-related cues are responsible for promoting germination from a long-lived soil seed bank in B. gigantea, a species occurring in seasonally waterlogged swamp heath, while vigorous resprouting and abundant flowering following fire is also documented for B. lamellata, which occurs on sandplains in fire-prone kwongan heathland (Cross et al. 2013; Conran et al. 2002; Lowrie 2014).

This study examined the germination biology of all six northern Australian Byblis species (B. aquatica, B. filifolia, B. guehoi, B, liniflora, B. pilbarana, and B. rorida). We explored the hypotheses that i) seasonal temperature and moisture conditions in combination with the naturally occurring germination stimulants $\mathrm{KAR}_{1}$ and ethylene are key ecological factors in the regulation of seed germination, and ii) dormancy and germination traits vary amongst seed populations from different habitats. To address these hypotheses we aimed to: 1) classify seed dormancy; 2) determine the dormancy break and germination responses to different light and temperature cues, particularly cold and warm stratification as well as dry afterripening; 3 ) test the effectiveness of $\mathrm{KAR}_{1}$ and ethylene as germination stimuli when combined with dormancy breaking-treatment; 4) examine whether seed dormancy and germination traits varied between seed populations from different habitats; and 5) determine whether these habitats experienced different environmental conditions (temperature and moisture in the upper soil profile) during desiccation of the substrate at the end of the wet season. The rapidity of desiccation directly affects the length of the growing season and the rate of onset of aridity, which are two important variables in ephemeral habitats (Cross et al. 2015b). 


\section{Seed collection}

Mature seeds (black and dehiscing) were collected from B. aquatica Lowrie \& Conran, B. filifolia Planch., B. guehoi Lowrie \& Conran, Byblis liniflora Salisb., B. pilbarana Lowrie \& Conran, and Byblis rorida Lowrie \& Conran during the late wet season (March-May) in 2012, 2015, or 2016 (Table 1). Multiple populations were sampled for the three most widespread species (B. filifolia [7 populations], B. liniflora [3 populations] and B. rorida [6 populations]) in order to assess variation in germination response and seed dormancy between different habitats. Sampled habitats included skeletal sandy soil lenses over sandstone pavement or granite supporting low herbaceous assemblages (SS), deeper soils on the aprons of sandstone pavements and massive sandstone supporting herbfields of mixed annual species (DS), and heavy cracking clays supporting mixed herbaceous species in open Eucalyptus woodland (CC).

\section{Table 1}

\section{Habitat characteristics}

Soil depth was measured at all seed collection sites by driving a thin metal rod $(1 \mathrm{~cm}$ diameter $)$ into the soil either until bedrock was contacted, or to a maximum depth of $150 \mathrm{~cm}$. Nine depth measurements were taken at each site, in a $3 \times$ 3 grid with 5 m spacing

A detailed assessment of the habitat characteristics of three species was carried out at sites on Theda Station (Table 1.) To determine the chemical composition and physical texture of soils, three replicate $500 \mathrm{~g}$ samples from four $B$. filifolia sites, two B. liniflora sites, and two B. rorida sites were collected and sent to ChemCentre (Bentley, Western Australia) for analytical determination of soil properties and chemical factors (Table 2). Soil moisture and temperature during the seed maturation period (17 March to 3 May 2016) were measured prior to seed collection at two sites each for SS, DS, and CC. Three S-SMC-M005 soil moisture and one S-TMB-M006 temperature smart sensors attached to a Micro Station data logger (Hobo H21-002, Onset, Bourne, USA) were inserted into undisturbed soil in open, unshaded areas. Byblis have shallow and poorly developed root systems (Lowrie 2014).

Following examination of the roots of excavated individuals sensors were at installed $2 \mathrm{~cm}$ below the soil surface to capture soil moisture and temperature in the upper soil profile. Soil temperature and moisture probes operated for 48 days, including 31 days without precipitation following the second of two significant rainfall events on the $19^{\text {th }}$ March $(39 \mathrm{~mm})$ and $31^{\text {st }}$ March- $1^{\text {st }}$ April $(41 \mathrm{~mm})$. The increase in soil volumetric moisture content $(\% \mathrm{v} / \mathrm{v})$ following each rainfall event was measured from the first data point of increasing moisture content to the maximum value reached (generally occurring within 12-24 h). However, damage from fauna to one logger resulted in only a single dataset for SS. Rainfall data was drawn from the Theda Station weather station (Australian Bureau of Meteorology, http://www.bom.gov.au/climate/data/) and all logger sites were located within $1 \mathrm{~km}$ of the weather station to minimise site-specific variation in rainfall. 
Seed collections of each species were pooled for each population, and were cleaned manually by gently rubbing fruits over $250 \mu \mathrm{m}$ to $2 \mathrm{~mm}$ gauge steel sieves with a handheld rubber stopper. Seeds were then separated from chaff and debris using a Zig Zag vacuum aspirator (Selecta Machinefabriek BV, Enkhuizen, The Netherlands) and stored in a controlled environment room at $15^{\circ} \mathrm{C}$ and $15 \%$ relative humidity prior to use in experiments. Seed size (measured digitally) and quality was determined for three replicates of 100 seeds from each population via X-ray analysis (MX20 digital X-ray cabinet, Faxitron, Tucson, USA). Seeds were scored as filled if the endosperm appeared as fully developed, not shrunken or retracted from the testa, and showed no signs of internal damage. Germination experiments were conducted on freshly collected seeds of B. filifolia, B. guehoi, B. liniflora and B. rorida, while seeds of $B$. aquatica and B. pilbarana were stored for 1-3 years prior to germination testing.

\section{Germination biology}

To assess the seed germination response to temperature, light, and germination stimulants, seeds of each population of each species were sterilised in a $2 \%$ calcium hypochlorite solution under vacuum for $30 \mathrm{~min}$, before being washed in sterile deionised water and plated in $90 \mathrm{~mm}$ Petri dishes onto $0.7 \%$ (w/v) water agar only (control) or on water agar containing $2.89 \mathrm{mM} \mathrm{GA}_{3}$ (Sigma Aldrich Chemicals, Australia), $1 \mu \mathrm{M} \mathrm{KAR}_{1}$ (Flematti et al. 2004), or on water agar after exposure to $50 \mathrm{nmol}$ ethylene gas $\left(\mathrm{C}_{2} \mathrm{H}_{4}\right)$ for $24 \mathrm{~h}$. Methods of ethylene exposure followed Cross et al. (2014). Four replicates of 25 seeds for each treatment were placed in incubators at constant $10,15,20,25,30$, or $35^{\circ} \mathrm{C}$ on a 12 $\mathrm{h}$ photoperiod, or in constant darkness (plated in darkness and wrapped in aluminium foil to exclude light). Germination (radicle emergence to $>1 \mathrm{~mm}$ ) was scored daily for one week then weekly for another seven weeks in light treatments, but once only after eight weeks in dark treatments.

To investigate the impact of cold and warm stratification on the alleviation of seed dormancy, additional replicates of 25 seeds were prepared as described previously for control, $\mathrm{GA}_{3}, \mathrm{KAR}_{1}$, and ethylene treatments. For stratification, four replicates for each treatment were incubated in Petri dishes on water agar at $10^{\circ} \mathrm{C}$ (cold stratification) or at $35^{\circ} \mathrm{C}$ (warm stratification) for 8 weeks, before transfer to $25^{\circ} \mathrm{C}$ for germination for a further 8 weeks. Seeds were cold or warm stratified under a $12 \mathrm{~h}$ photoperiod and then incubated at $25^{\circ} \mathrm{C}$ under either a $12 \mathrm{~h}$ photoperiod, or in constant darkness. Four replicates of each treatment incubated at constant 10,25 , or $35^{\circ} \mathrm{C}$ for 16 weeks served as control seeds. Germination was scored weekly in light/dark treatments, and at the conclusion of the full 16-week period in dark treatments.

To determine the effect of dry afterripening on dormancy alleviation, seeds of each species were enclosed in a polycarbonate electrical enclosure box $(28 \times 28 \times 14 \mathrm{~cm}$; NHP Fibox, Richmond, Australia) above a non-saturated solution of $\mathrm{LiCl}\left(364 \mathrm{gL}^{-1}\right)$ creating a relative humidity of $50 \%$ (Hay et al. 2008), and placed at constant $30^{\circ} \mathrm{C}$ (Tuckett et al. 2010). After 1 and 3 months, four replicates of 25 seeds were extracted and incubated at $25^{\circ} \mathrm{C}$ under a $12 \mathrm{~h}$ photoperiod on water agar, or exposed to either $\mathrm{GA}_{3}, \mathrm{KAR}_{1}$, and ethylene treatments as previously described. Germination was scored weekly for 8 weeks of incubation.

Upon completion of each experiment, all non-germinated seeds were cut-tested to determine viability with seeds possessing a firm, white endosperm and embryo judged to be viable. Germination percentages are therefore based on the number of viable seeds. 
Embryo growth

To determine whether any embryo growth occurs inside Byblis seeds prior to radicle emergence, and thus if the seeds have morphological/morphophysiological dormancy (Baskin and Baskin 2014), 100 seeds of each population of each species were incubated on water agar after exposure to $2.89 \mathrm{mM} \mathrm{GA}_{3}$ and incubated at $25^{\circ} \mathrm{C}$ on a 12-h photoperiod. Prior to incubation and after each week for 8 weeks, ten seeds were randomly selected and dissected, with the seed and embryo length for each measured under a dissecting microscope equipped with an ocular micrometer to determine the embryo length to seed length (E:S) ratio.

\section{Statistical analyses}

One-way ANOVA with Tukey post-hoc tests were used to assess variation in soil depth, chemistry factors, soil temperature and moisture content, and germination percentages for each population between habitat types. Linear regression was used to test the effect of soil depth on soil surface temperature (daily maximum, minimum, and mean temperature, and maximum, minimum, and mean diurnal temperature variation) and surface hydrology (volumetric moisture increase following rainfall, mean daily volumetric moisture loss, maximum daily volumetric moisture loss, and minimum volumetric moisture content).

Binary logistic regression was used to assess the main and interaction effects of light, temperature, $\mathrm{GA}_{3}, \mathrm{KAR}_{1}$, ethylene, stratification, and after-ripening on seed germination. One-way ANOVA with Tukey post-hoc tests were used to test the effect of incubation duration on embryo length. Preliminary analyses of all data were conducted to test the assumptions of normality (Kolmogorov-Smirnov test), linearity and homoscedasticity (Levene's test). Where necessary, data were $\log _{10}$ transformed to help meet assumptions of normality and equal variance. All statistical tests were conducted using the $95 \%$ confidence interval (CI), with significance determined by $P<0.05$. Data are presented as mean \pm 1 s.e. of the raw data unless stated otherwise.

\section{Results}

\section{Habitat characteristics}

All sampled soils were low in nutrients, varying significantly only in carbon and nitrogen content (Table 2). Soils contained low concentrations of nitrogen $(<0.2 \mathrm{mg} / \mathrm{kg}$ ), phosphorus $(<8.0 \mathrm{mg} / \mathrm{kg})$, and potassium (ca. $17 \mathrm{mg} / \mathrm{kg})$. Soil at CC sites was deep ( $>150 \mathrm{~cm}$ ) fine-textured sandy clay. Soil at SS and DS sites consisted of fine to coarse-textured sandy loam. Average soil depth was approximately three times greater $(P=0.008)$ at DS sites $(40-100 \mathrm{~cm})$ than SS sites $(<20 \mathrm{~cm})$.

\section{Table 2}

The three sampled habitats exhibited markedly different hydrological and thermal conditions in the upper soil profile 
during desiccation of the substrate at the end of the wet season (Table 3). Soil moisture content remained relatively constant in the two CC sites over the monitoring period, but declined rapidly in shallow-soil SS and DS habitats (Fig. 1). The persistence of soil moisture in SS and DS sites was strongly related to soil depth, with mean and maximum daily volumetric moisture loss strongly positively associated with increasing soil depth ( $P<0.001$ in both cases). Mean daily moisture loss was approximately $20 \%$ greater in SS sites (nearly $0.7 \%$ per day) compared with DS (Fig. 1).

Highest temperatures and greatest diurnal temperature variation were recorded from shallow-soil habitats (Table 3).

Linear regression analyses provided strong negative correlations in all cases $(P<0.001)$ between increasing soil depth and both daily temperature (mean, maximum and minimum) and diurnal temperature variation (maximum, minimum, and mean). The surface soil of SS and DS sites frequently exceeded $40^{\circ} \mathrm{C}$, and daily minimum temperature was consistently $1-2^{\circ} \mathrm{C}$ greater than at CC sites (Fig. 1). Temperature patterns were similar for SS and DS sites, although soil moisture in SS was completely recharged by a rainfall event on $31^{\text {st }}$ March $-1^{\text {st }}$ April while nearby DS sites showed only a slight increase in surface soil moisture (ca. 2\%). As a result, surface soils at both DS sites dried almost completely over the monitoring period (to ca. $1 \%$ moisture content) while soil moisture remained at $12 \%$ after 31 days

\section{Table 3}

\section{Figure 1}

\section{Germination biology}

Seed viability was high (>80\%) in all species (Table 4). Germination of fresh untreated seeds was negligible (0-12\%) across all temperatures for all populations of B. filifolia, B. liniflora, and B. rorida, and occurred predominantly at $20^{\circ} \mathrm{C}$ and $25^{\circ} \mathrm{C}$ (Fig. 2). Untreated seeds (water agar controls) germinated to relatively high percentages in light/dark treatments for B. aquatica $\left(60 \pm 4 \%\right.$ at $\left.20^{\circ} \mathrm{C}\right)$, B. guehoi $\left(90 \pm 10 \%\right.$ at $\left.20^{\circ} \mathrm{C}\right)$ and B. pilbarana $\left(67 \pm 14 \%\right.$ at $\left.30^{\circ} \mathrm{C}\right)$.

$\mathrm{GA}_{3}$ exposure significantly improved seed germination percentage for all populations of $B$. filifolia, B. liniflora and $B$. rorida $(P<0.001$ in all cases; Fig. 2$)$. GA 3 exposure widened the temperature at which significant germination occurred to include $30^{\circ} \mathrm{C}$ in B. filifolia, and $30^{\circ} \mathrm{C}$ and $35^{\circ} \mathrm{C}$ in B. guehoi, B. liniflora and B. rorida. Germination response to $\mathrm{GA}_{3}$ exposure was greater in populations of B. filifolia, B. liniflora and B. rorida from SS (Fig. 2), being on average ca. $50 \%$ higher in SS than DS for $B$. filifolia $(P=0.032, \mathrm{~F}=8.7)$, ca. $65 \%$ higher in SS than DS for $B$. rorida $(P<0.001, \mathrm{~F}=219.7)$, and ca. $40 \%$ higher in SS than CC for $B$. liniflora (Fig. 2). The main effect of $\mathrm{GA}_{3}$ exposure on germination percentage was not significant for B. aquatica $(P=0.078)$ or B. pilbarana $(P=0.660)$.

The germination of freshly collected seeds was markedly higher in seeds exposed to $\mathrm{KAR}_{1}$ or ethylene than in water agar control seeds, in at least one incubation temperature (Fig. 2), for all six species (Table 5). KAR exposure $^{2}$ 
increased seed germination for six of the seven populations of B. filifolia (6-47\% increase), both CC populations of $B$. liniflora (47-53\% increase), and three of the four SS populations of B. rorida (2-28\% increase). $\mathrm{KAR}_{1}$ exposure also increased germination for B. guehoi (up to $21 \%$ increase) and B. pilbarana (up to $32 \%$ increase), but suppressed germination of B. aquatica (Fig. 2). Ethylene exposure increased germination in all three SS populations of $B$. filifolia (6-31\% increase) and two of the four SS populations of $B$. rorida (4-62\% increase), but suppressed germination of $B$. pilbarana and B. guehoi by up to $55 \%$ and $34 \%$, respectively (Fig. 2).

\section{TABLE 4}

Most germination across all species was observed in treatments incubated under 12/12 hr photoperiod. No germination

No species exhibited a significantly enhanced germination response to cold stratification for 8 weeks at $10^{\circ} \mathrm{C}$ or warm stratification for 8 weeks at $35^{\circ} \mathrm{C}$ compared with non-stratified seeds in any treatment (data not shown).

Although afterripening for 1 or 3 months did not increase the germination of seeds incubated in water $(P=0.052$, $0.611,0.221$, and 0.994 for F6, F7, R5, and R6, respectively), the main effect of afterripening on the germination of seeds exposed to both $\mathrm{KAR}_{1}$ and ethylene was highly significant in all four tested populations of $B$. filifolia and $B$. rorida $(P<0.001$ in all cases). Following afterripening for 3 months, germination increased by $24-32 \%$ (B. filifolia) and $27-63 \%$ (B. rorida) for seeds incubated in $\mathrm{KAR}_{1}$, and by $25-40 \%$ (B. filifolia) and 29-50\% (B. rorida) for seeds exposed to ethylene (Fig. 3). The germination response of seeds to $\mathrm{GA}_{3}$ exposure after 3 months of afterripening also increased by up to $30 \%$ in B. filifolia and by up to $23 \%$ in B. rorida $(P=<0.001$ in both cases).

\section{Table 5}

\section{Figure 3}

\section{Embryo characteristics}

The seeds of all species possessed an axile, linear embryo occupying roughly one-quarter of the seed volume (Table 4). No significant embryo growth occurred in any species prior to the emergence of the radicle.

\section{Discussion}

This study provides evidence of fine-scale local variation in the depth of physiological seed dormancy and germination cues between populations of tropical Byblis. Seasonal temperature and moisture conditions, in combination with 
naturally occurring germination stimuli such as $\mathrm{KAR}_{1}$ and ethylene, appear to be major environmental factors regulating seed dormancy and germination. Data show that a degree of phenotypic plasticity in seed dormancy exists within the tested species. This is coincident with different seed accessions arising from plant populations that vary in microhabitat factors such as soil temperature and the persistence of soil moisture. Each of the three seasonally wet habitats studied clearly represents a distinct environmental niche, and similar patterns of intraspecific plasticity were observed in the seed dormancy depth and germination response of sympatric species between these habitats. Studied species exhibited similar seed germination responses across the sampled range of substrates, suggesting that variation in seed germination traits may reflect localised adaptation.

\section{Seeds of all six tropical Byblis species exhibit non-deep physiological dormancy (PD), as determined by low} germination (or temperature-conditional germination) of freshly collected or stored untreated seeds, the presence of a fully developed linear embryo, and a strong response to $\mathrm{GA}_{3}$ (Baskin and Baskin 2014). Although we acknowledge that the storage of B. aquatica and B. pilbarana seeds prior to experimental use may have influenced dormancy depth, both species exhibited similar germination patterns in response to light, temperature and germination stimuli to those of freshly collected seeds from other tested species. Non-deep PD has previously been demonstrated for the south western Australian endemic Byblis gigantea (Cross et al. 2013), as well as for many species from numerous other families in the Lamiales (Baskin and Baskin 2014). Data from this study suggest that dormancy loss in tropical Byblis (at least in B. filifolia and B. rorida) occurs following a period of warm dry afterripening. This is probably reflective of conditions experienced by seeds in the soil seed bank during the April-November dry season. Seedling emergence in most tropical Byblis occurs after early wet season rainfall in November-December (A Cross and M Barrett, pers. obs.). The alleviation of dormancy during the dry season would result in seeds being non-dormant and rapidly able to exploit soil moisture at the onset of the summer growing season. Afterripening is a common method facilitating the maintenance of seeds through warm dry periods in unpredictable, highly seasonal environments such as northern Australia (McIvor and Howden 2000; Tuckett et al. 2010; Carta et al. 2013), and has been shown to alleviate seed dormancy in a number of other species from seasonally wet habitats in the Kimberley (Cross et al. 2015a).

Untreated seeds of all six species required exposure to light to germinate and germinated predominantly at $20-25^{\circ} \mathrm{C}$, with the exception of the more arid-climate B. pilbarana which germinated optimally at $30^{\circ} \mathrm{C}$. Light exposure appears to be a relatively common requirement for germination in the seeds of species with non-deep PD and may be a depthsensing mechanism in aquatic habitats subject to periodic inundation (Pons 2000; Baskin and Baskin 2014). Indeed, the seeds of many species from ephemeral wetland habitats, including annual aquatic herbs from shallow freshwater rock pools on sandstone in the northern Kimberley, exhibit an absolute light requirement (e.g. Tuckett et al. 2010a,b; Carta et al. 2013; Cross et al. 2014, 2015a). Additionally, as the seeds of all studied Byblis species are small they may lack the resources to emerge if seeds were buried in darkness.

Smoke-derived $\mathrm{KAR}_{1}$, and to a lesser extent ethylene, plays a significant role in promoting seed germination in tropical Byblis. Dormancy status significantly influences the amplitude of this germination response and mechanisms such as afterripening may work synergistically with naturally occurring stimulants such as $\mathrm{KAR}_{1}$ and ethylene for species with non-deep PD (Merritt et al. 2007; Turner et al. 2009). Exposure to smoke stimulates the germination of numerous species with different life histories from the seed bank of fire-prone savanna habitats in northern Australia (Williams et al. 2003; Clarke and French 2005), including ephemeral wetland habitats (Cross et al. 2015a). Indeed, 
smoke-derived chemicals are a common germination cue in many fire-prone ecosystems worldwide (e.g., Brown 1993; Dixon et al. 1995; Pierce et al. 1995; Roche et al. 1998; Morris 2000). Although soil lenses on large areas of sandstone pavement probably burn less frequently than the surrounding savanna matrix as sandstone outcrops and pavements are considered to be areas of fire refugia (Bowman et al. 2010), these areas almost certainly experience significant ash deposition during fires and the washing of this material into soil lenses and apron habitats by rainfall could result in a strong $\mathrm{KAR}_{1}$ signal. Ethylene is recognised as a notable germination cue in a variety of habitats worldwide (Baskin and Baskin 2014). Biogenic ethylene, which originates predominantly from the decomposition of organic matter by soil microbes (Arshad and Frankenberger 1990; Jackel et al. 2004), has recently been implicated as a major germination stimulant for the inhabitant flora of seasonally wet habitats in the North Kimberley (Cross et al. 2014, 2015a). Emergence from the seed bank in ephemeral wetland habitats is likely to be regulated by the response of the sediment microbial community to the depth and duration of flooding (Cross et al. 2014). This potentially explains why the greatest germination response to ethylene was observed in seeds of B. aquatica and populations of B. filifolia and $B$. rorida from shallower soils.

The longevity and predictability of seasonal water availability, as well as localised climatic factors in the parental environment, are drivers of plasticity in germination traits (e.g., Gutterman 2000; Baskin and Baskin 2014; Long et al. 2014). Individuals from populations in warmer, drier environments appear to produce less dormant seeds than populations of the same species in cooler, wetter areas (Probert 2000; Steadman et al. 2004; Hoyle et al. 2008; Baskin and Baskin 2014). Freshly collected seeds of B. liniflora and B. rorida from populations in the King Leopold Ranges in the south western part of the North Kimberley (L2 and R4) germinated to higher percentages than seeds from populations on the Gardner Plateau in the central North Kimberley (L1 and L3, and R1, R2, R3, R5, and R6), corresponding with significantly lower annual rainfall and higher average seasonal temperatures in the former region (McKenzie et al. 2009). Depth of seed dormancy and the degree of sensitivity to germination stimulants also varied markedly between sampled habitats at local scale. Seeds of both B. filifolia and B. rorida from SS habitats germinated to significantly higher percentages (50-65\% greater) than those from DS habitats after exposure to $\mathrm{GA}_{3}$, indicating weaker PD in seeds from SS habitats. Similarly, seed germination after exposure to $\mathrm{GA}_{3}$ was ca. $40 \%$ greater for seeds of $B$. liniflora from shallow sandy soils compared those from deeper cracking clays.

Hydroperiod (persistence of soil moisture) during the seed maturation period in shallow sandy soils was strongly positively associated with soil depth, with rates of daily moisture loss nearly $20 \%$ greater in soil lenses ( $<20 \mathrm{~cm}$ deep) compared with apron areas (30-70 cm deep). The hydrological stability of CC sites compared with sandy soils is likely to reflect the higher water retention capacity of heavy cracking clays rather than soil depth (Table 1). Soil lenses over bedrock depressions are reservoirs fed by the surrounding rock catchment in a similar fashion to freshwater rock pools (FRP) on exposed rock (though at larger scale and without persistent free-standing water). The soil moisture data obtained in this study indicate that the hydrology and hydroperiod of soil lenses over sandstone are similar to those of FRP in the Kimberley (Cross et al. 2015b). Shallower habitats experience higher temperatures and greater diurnal temperature fluctuation, and despite desiccating with much greater rapidity than deeper depressions, they can be fully recharged by even small rainfall events. The study site has between 36-130 rainfall days each year during the November to April wet season, interspersed with between 2-15 drought periods of mean duration 10.4 days on average (Cross et al. 2015b). This suggests that even though the duration and timing of moisture availability in SS 
habitats might be unpredictable, in most years rainfall probably occurs with sufficient regularity to recharge most shallow-soil systems for a period long enough to ensure reproductive success.

Results from this study further highlight the length of the growing season as a driver of ecology in the monsoon tropics, and provide additional evidence of the importance of ethylene and the smoke-derived chemical $\mathrm{KAR}_{1}$ as seed germination stimuli in seasonally wet habitats. The plasticity in seed dormancy and seed germination traits observed for tropical Byblis may reflect the need for resilience within seed populations to the seasonal climatic extremes and environmental stochasticity of northern Australia. Many species inhabiting seasonally wet habitats in northern Australia exhibit wide geographical distribution and high occupancy of large-scale wetland habitats (e.g., Wheeler 1992; Cowie et al. 2000), while range-restricted species are more frequently associated with small-scale and highly ephemeral habitats (Cross 2014; Cross et al. 2015b). If ephemerality in the tropics has such a strong impact on seed ecology as has been hypothesised (Clary 2008; Cross et al. 2015a), then range-restricted ecological specialists in northern Australia are likely to possess among the most resilient and finely tuned seed dormancy and germination strategies of any vegetation communities in Australia. Future studies should examine a wider suite of marginal and ephemeral aquatic taxa in the monsoon tropics, to elucidate in greater detail habitat-specific variation in seed dormancy and germination response both within and between species over longer periods. Multi-generational and reciprocal transplant studies would also be desirable to differentiate between maternal effects and fixed adapted traits.

\section{Acknowledgements}

Allen Lowrie is thanked for providing seeds of B. aquatica and B. pilbarana, and Greg Allan for providing seeds of $B$. guehoi. Cecilia Myers and staff at Theda and Doongan Stations are particularly thanked for their hospitality and support. The authors declare no conflicts of interest.

\section{References}

Andersen AN, Woinarski JCZ, Parr KL (2012) Savanna burning for biodiversity: fire management for faunal conservation in Australian tropical savannas. Austral Ecology 37, 658-667.

Aponte C, Kazakis G, Ghosn D, Papanastasis VP (2010) Characteristics of the soil seed bank in Mediterranean temporary ponds and its role in ecosystem dynamics. Wetlands Ecology and Management 18, 243-253.

Arshad M, Frankenberger WT (1990) Production and stability of ethylene in soil. Biology and Fertility of Soils 10, 2934.

AVH (2016) Australia's Virtual Herbarium, Council of Heads of Australasian Herbaria, < http://avh.chah.org.au $>$, accessed 23 November 2016.

Barrett RL, Barrett MD (2015) Twenty-seven new species of vascular plants from Western Australia. Nuytsia 26, 2187. 
Baskin CC, Baskin JM (2014) 'Seeds. Ecology, biogeography, and evolution of dormancy and germination'.

(Academic Press: San Diego)

446

Bostock PD, Holland AE (2016) Census of the Queensland Flora 2016. Queensland Department of Science, Information Technology and Innovation: Brisbane. https://data.qld.gov.au/dataset/census-of-the-queensland-flora$\underline{2016}$, accessed 1 September 2016.

Bowman DMJS, Brown GK, Braby MF, Brown JR, Cook LG, Crisp MD, Ford F, Haberle S, Hughes J, Isagi Y, Joseph L, McBride J, Nelson G, Ladiges PY (2010) Biogeography of the Australian monsoon tropics. Journal of Biogeography 37, 201-216.

Brock MA (2011) Persistence of seed banks in Australian temporary wetlands. Freshwater Biology DOI:10.1111/j.1365-2427.2010.02570.x.

Brown NAC (1993) Promotion of germination of Fynbos seeds by plant-derived smoke. New Phytologist 123, 575583.

Carta A, Bedini G, Müller JV, Probert RJ (2013) Comparative seed dormancy and germination of eight annual species of ephemeral wetland vegetation in a Mediterranean climate. Plant Ecology 214, 339-349.

Clarke S, French K (2005) Germination response to heat and smoke of 22 Poaceae species from grassy woodlands. Australian Journal of Botany 53, 445-454.

Clary J (2008) Rainfall seasonality determines annual/perennial grass balance in vegetation of Mediterranean Iberian. Plant Ecology 195, 13-20.

Cochrane A, Yates CJ, Hoyle GL, Nicotra AB (2015) Will among-population variation in seed traits improve the chance of species persistence under climate change? Global Ecology and Biogeography 24, 12-24.

Conran JG, Lowrie A, Moyle-Croft J (2002) A revision of Byblis (Byblidaceae) in south-western Australia. Nuytsia 15, 11-19.

Cowie ID, Short PS, Osterkamp Madsen M (2000) 'Floodplain flora: a flora of the coastal floodplains of the Northern Territory, Australia'. Flora of Australia supplementary series 10. (Australian Biological Resources Study: Canberra)

Cross AT (2014) 'Between a rock and a hard place: community structure, seasonal ecology, and local adaptation in ephemeral arid-tropical freshwater rock pools’. PhD Thesis (University of Western Australia: Perth)

Cross AT, Merritt DJ, Turner SR, Dixon KW (2013) Seed germination of the carnivorous plant Byblis gigantea (Byblidaceae) is cued by warm stratification and karrikinolide. Botanical Journal of the Linnean Society 173, 143-152. 
Cross AT, Cawthray GR, Merritt DJ, Turner SR, Renton M, Dixon KW (2014) Biogenic ethylene promotes seedling emergence from the sediment seed bank in an ephemeral tropical rock pool habitat. Plant and Soil 380, 73-87.

Cross AT, Turner SR, Renton M, Baskin J, Dixon KW, Merritt DJ (2015a) Seed dormancy and persistent seed banks of ephemeral freshwater rock pools in the Australian Monsoon Tropics. Annals of Botany 115, 847-859.

Cross AT, Turner SR, Merritt DJ, van Niekerk A, Renton M, Dixon KW, Mucina L (2015b) Vegetation patterns and hydrogeological drivers of freshwater rock pool communities in the monsoon-tropical Kimberley region, Western Australia. Journal of Vegetation Science 26, 1184-1197.

Cross AT, Davis A, Fleischmann A, Horner JD, Jürgens A, Merritt DJ, Murza GL, Turner SR (2018) Reproductive biology and prey-pollinator conflicts. In: L Adamec L, A Ellison (Eds) 'Carnivorous Plants: physiology, ecology, and evolution'. (Oxford University Press: London).

Deil U (2005) A review on habitats, plant traits and vegetation of ephemeral wetlands - a global perspective. Phytocoenologia 35, 533-705.

Dixon KW, Roche S, Pate JS (1995) The promotive effect of smoke derived from burnt native vegetation on seed germination of Western Australian plants. Oecologia 101, 185-192.

Donohue K, Schmitt J (1998) 'Maternal environmental effects in plants: adaptive plasticity'. In: TA Mousseau, CW Fox (Eds) Maternal Effects as Adaptations. pp 137-158. (Oxford University Press: New York)

Finlayson CM (2005) Plant ecology of Australia's tropical floodplain wetlands: a review. Annals of Botany 96, 541555 .

Flematti G, Ghisalberti E, Dixon K, Trengove R (2004) A compound from smoke that promotes seed germination. Science 305, 977.

Garnett ST, Williamson G (2010) Spatial and temporal variation in precipitation at the start of the rainy season in tropical Australia. The Rangeland Journal 32, 215-226.

Graham G (2002) North Kimberley 1 (NK1- Mitchell Subregion). In A Biodiversity Audit of Western Australia's 53 Biogeographical Subregions in 2002. (Department of Conservation and Land Management: Perth)

Graham G, McKenzie NL (2003) A conservation case study on Western Australia's Mitchell subregion (North Kimberley 1) in 2003. (Department of Conservation and Land Management: Perth)

Gutterman Y (2000) Maternal effects on seeds during development. In Seeds: The Ecology of Regeneration in Plant Communities (ed. M. Fenner). pp. 59-84. (CABI Publishing: UK) 
Handasyde T (2005) Report on compilation of Kimberley biodiversity and natural resource management data and associated information. (Kimberley Regional Fire Management Project, Natural Heritage Trust: Perth)

Hay F, Adams J, Manger K, Probert R (2008) The use of non-saturated lithium chloride solutions for experimental control of seed water content. Seed Science and Technology 36, 737-746.

Hoyle GL, Steadman KJ, Daws MI, Adkins SW (2008) Pre-and post-harvest influences on seed dormancy status of an Australian Goodeniaceae species, Goodenia fascicularis. Annals of Botany 102, 93.

Krieger A, Porembski S, Barthlott W (2003) Temporal dynamics of an ephemeral plant community: species turnover in seasonal rock pools on Ivorian inselbergs. Plant Ecology 167, 283-292.

James CS, Capon SJ, White MG, Rayburg SC, Thomas MC (2007) Spatial variability of the soil seed bank in a heterogenous ephemeral wetland system in semi-arid Australia. Plant Ecology 190, 205-217.

Ladygina N, Dedyukhina EG, Vainshtein MB (2006) A review on microbial synthesis of hydrocarbons. Process Biochemistry 41, 1001-1014.

Leck MA, Brock MA (2000) Ecological and evolutionary trends in wetlands: evidence from seeds and seed banks in New South Wales, Australia and New Jersey, USA. Plant Species Biology 15, 97-112.

Lin Z, Zhong S, Grierson D (2009) Recent advances in ethylene research. Journal of Experimental Botany 60, 33113336.

Long RL, Gorecki MJ, Renton M, Scott JK, Colville L, Goggin DE, Commander LE, Westcott DA, Cherry H, FinchSavage WE (2014) The ecophysiology of seed persistence: a mechanistic view of the journey to germination or demise. Biological Reviews. DOI:10.1111/brv.12095.

Lowrie A (2014) 'Carnivorous plants of Australia. Volume 1'. (Redfern Natural History Productions: Poole)

Lowrie A, Conran JG (1998) A taxonomic revision of the genus Byblis (Byblidaceae) in northern Australia. Nuytsia 12, 59-74.

Lowrie, A., Conran, J.G. (2007) Byblis guehoi (Byblidaceae), a new species from the Kimberley, Western Australia. Telopea 12, 23-29.

McIvor, J.G., Howden, S.M. (2000) Dormancy and germination characteristics of herbaceous species in the seasonally dry tropics of northern Australia. Austral Ecology 25, 213-22.

McKenzie NL, Start AN, Burbidge AA, Kenneally KF, Burrows ND (2009) 'Protecting the Kimberley: A synthesis of scientific knowledge to support conservation management in the Kimberley region of Western Australia'. (Department 
of Environment and Conservation: Perth)

Merritt D, Turner S, Clarke S, Dixon K (2007) Seed dormancy and germination stimulation syndromes for Australian 571

Morris EC (2000) Germination response of seven east Australian Grevillea species (Proteaceae) to smoke, heat exposure and stratification. Australian Journal of Botany 48, 179-189.

Northern Territory Herbarium (2015) FloraNT Northern Territory Flora Online. Department of Land Resource Management, Viewed 23 November 2016 <http://eflora.nt.gov.au>

Pierce SM, Esler K, Cowling RM (1995) Smoke-induced germination of succulents (Mesembryanthemaceae) from fire-prone and fire-free habitats in South Africa. Oecologia 102, 520-522.

Pons TL (2000) 'Seed responses to light.' In M. Fenner (Ed) Seeds: The Ecology of Regeneration in Plant Communities. pp. 237-260. (CABI Publishing: UK)

Probert RJ (2000) 'The role of temperature in the regulation of seed dormancy and germination'. In M. Fenner (Ed) Seeds: The Ecology of Regeneration in Plant Communities. pp. 261-292. (CABI Publishing: UK)

Roche S, Dixon KW, Pate JS (1998) For everything a season: smoke-induced seedling recruitment in a Western Australian Banksia woodland. Austral Ecology 23, 111-120.

Russel-Smith J, Yates CP (2007) Australian savanna fire regimes: context, scale, patchiness. Fire Ecology 3, 48-63.

Thompson K, Grime JP (1979) Seasonal variation in the seed banks of herbaceous species in ten contrasting habitats. Journal of Ecology 67, 893-921.

Tuckett RE, Merritt DJ, Hay FR, Hopper SD, Dixon KW (2010a) Comparative longevity and low-temperature storage of seeds of Hydatellaceae and temporary pool species of south-west Australia. Australian Journal of Botany 58, 327 334.

Tuckett RE, Merritt DJ, Hay FR, Hopper SD, Dixon KW (2010b) Dormancy, germination and seed bank storage: a study in support of ex situ conservation of macrophytes of southwest Australian temporary pools. Freshwater Biology 55, 1118-1129.

Turner S, Merritt D, Ridley E, Commander L, Baskin J, Baskin C, Dixon K (2006) Ecophysiology of seed dormancy in the Australian endemic species Acanthocarpus preissii (Dasypogonaceae). Annals of Botany 98, 1137-1144. 
Turner SR, Dixon KW (2009) Seed dormancy and germination in the Australian baobab, Adansonia gregorii F. Muell.

612 Turner SR, Merritt DJ, Renton MS, Dixon KW (2009) Seed moisture content affects afterripening and smoke

613 responsiveness in three sympatric Australian native species from fire-prone environments. Austral Ecology 34, 866-

614877

Setterfield SA (2002) Seedling establishment in an Australian tropical savanna: effects of seed supply, soil disturbance and fire. Journal of Applied Ecology 39, 949-959.

Vigilante T, Bowman DMJS (2004a) Effects of fire history on the structure and floristic composition of woody vegetation around Kalumburu, North Kimberley, Australia: a landscape-scale natural experiment. Australian Journal of Botany 52, 381-404.

Vigilante T, Bowman DMJS (2004b) Effects of individual fire events on the flower production of fruit-bearing tree species, with reference to Aboriginal people's management and use, at Kalumburu, North Kimberley, Australia. Australian Journal of Botany 52, 405-415.

Western Australian Herbarium (1998-) FloraBase: the Western Australian Flora. Department of Parks and Wildlife. https://florabase.dpaw.wa.gov.au/

Wheeler JR (1992) 'Flora of the Kimberley region'. (Department of Conservation and Land Management: Perth)

Williams P, Whitfield M, Biggs J, Bray S, Fox G, Nicolet P, Sear D (2003) Comparative biodiversity of rivers, streams, ditches and ponds in an agricultural landscape in Southern England. Biological Conservation 115, 329-341.

Woinarski JCZ, Mackey B, Nix HA, Traill B (2007) 'The nature of northern Australia: its natural values, ecological processes and future prospects'. (Australian National University EPress: Canberra) 
Figure 1. Daily minimum and maximum temperature (top) and volumetric moisture curves in response to rainfall (bottom) for soil at $2 \mathrm{~cm}$ depth in tropical Byblis habitats in the central North Kimberley during the late wet season seed maturation period. A- heavy cracking clays supporting open Eucalyptus woodland (CC); B- shallow soil lenses on sandstone aprons supporting sparse herbaceous assemblages (SS); C- deeper soil lenses between exposed sandstone pavements supporting low herbfields (DS). Each curve represents the data from a single probe for temperature, and the averaged data from three probes for volumetric moisture. Loggers were established at two sites for each habitat type (solid and dotted lines, respectively), but damage to one logger resulted in only a single dataset for B.

Figure 2. Germination (mean probability with exact binomial 95\% confidence limits) of the seeds of six tropical Byblis species following eight weeks of incubation at five different incubation temperatures under alternating light/dark conditions ( $12 \mathrm{~h} / 12 \mathrm{~h}$ ) from either shallow soil lenses on sandstone aprons supporting sparse herbaceous assemblages (SS, closed symbols), deeper soil lenses between exposed sandstone pavements supporting low herbfields (DS, open symbols), or heavy cracking clays supporting open Eucalyptus woodland (CC, crosses). For each treatment combination, four replicates of 25 seeds were assessed. 
A

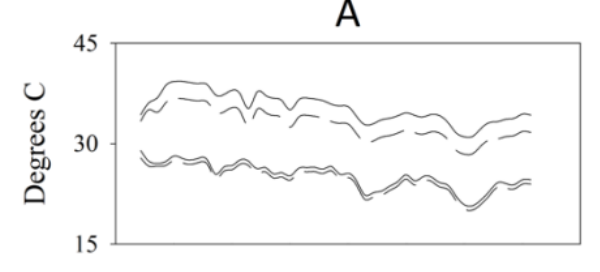

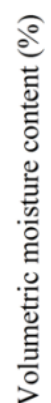

690

691

692

693

694

695

696

697

698

699

700

701

702

703

704

705

706

707

708

709

710

711

712

713

714

715

716

717

718

Date

Figure 1.

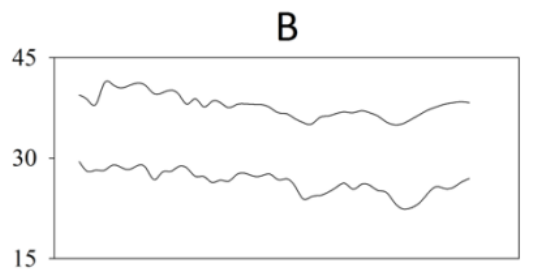

C
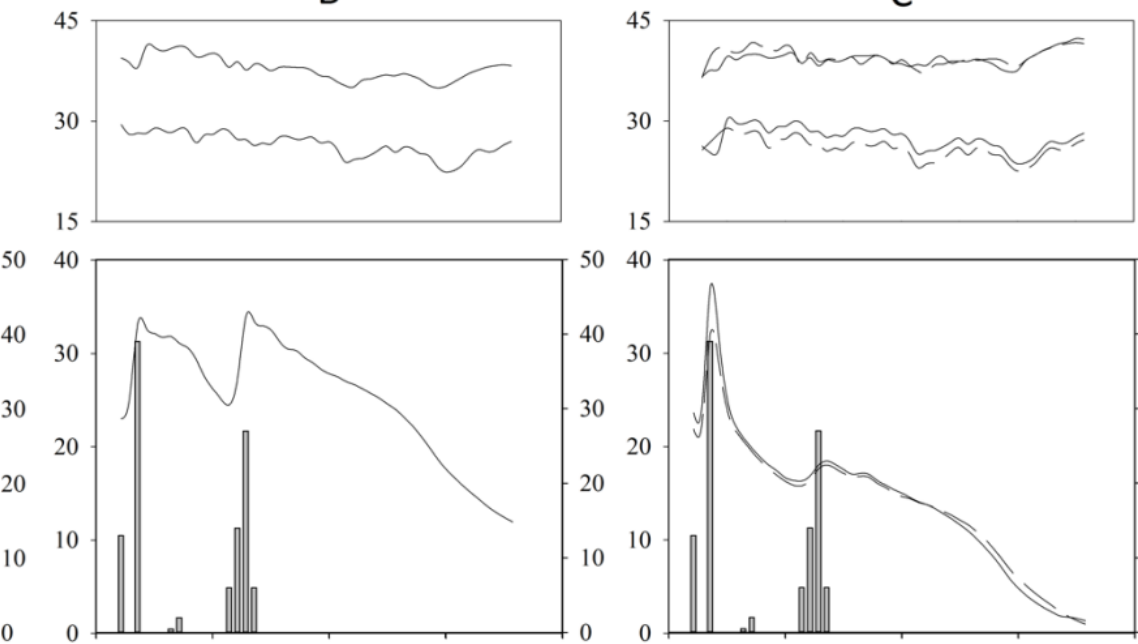

$50 \square^{50}$

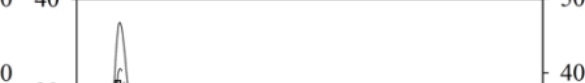

0

雪

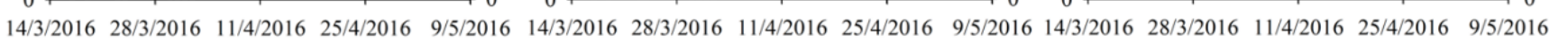

Date

Date 

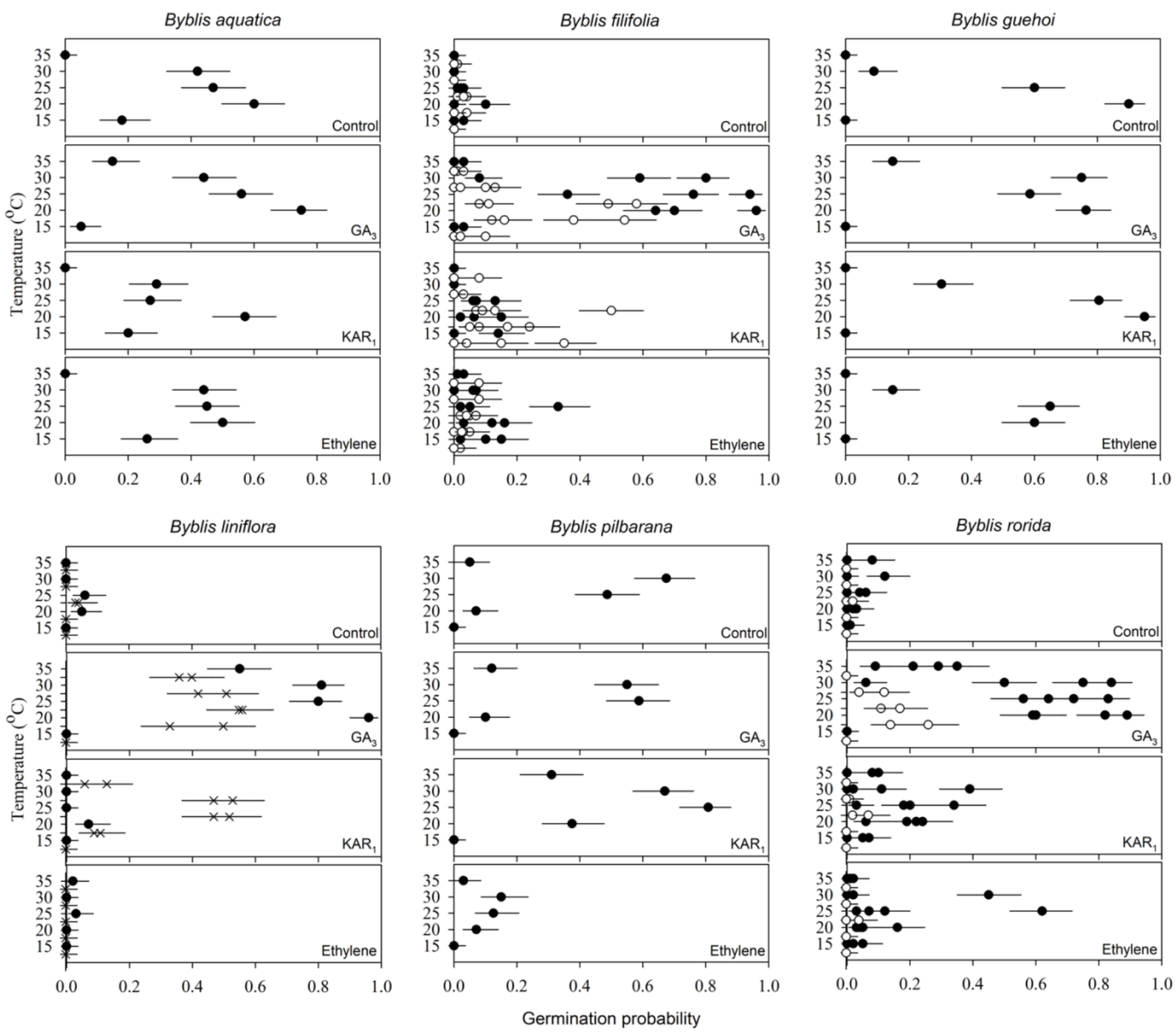

721 Figure 2. 


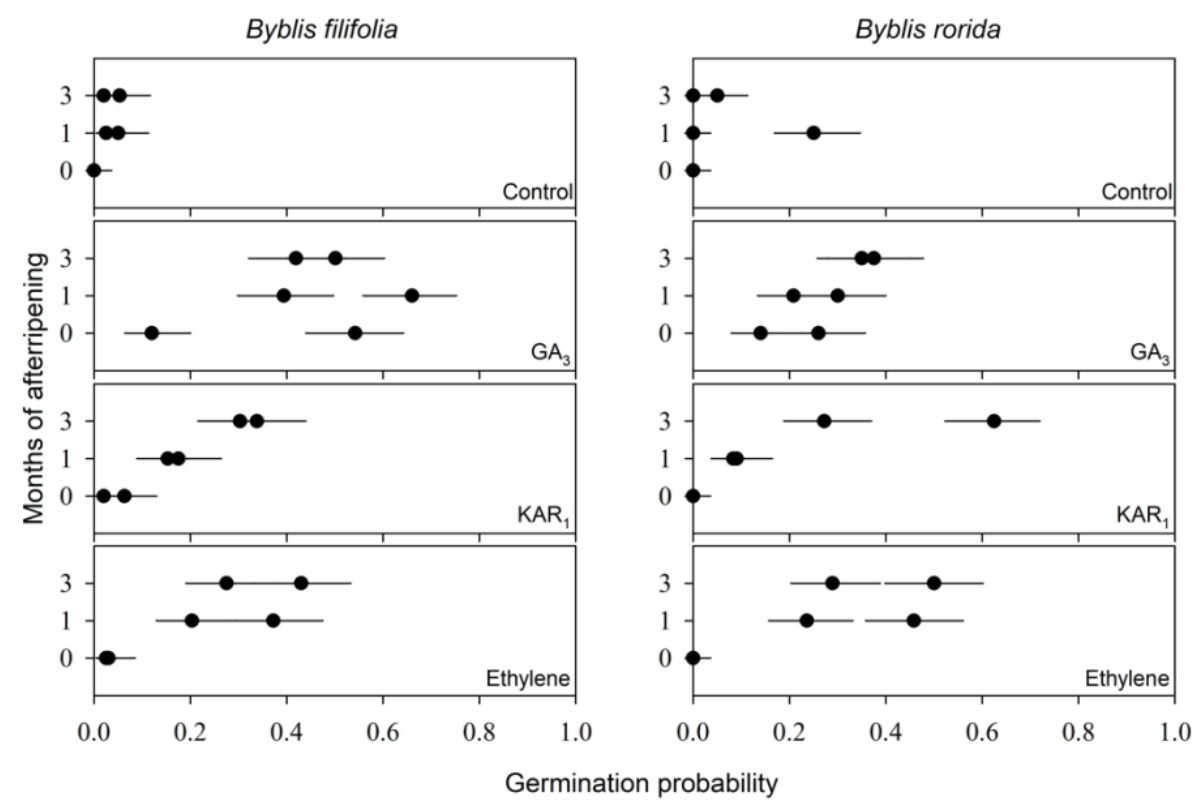

736

737 Figure 3. 